\title{
The correlation of major risk factors and clinicopathological characteristics in colorectal cancer patients under the age of 50
}

\author{
Ali Kagan Coskun • Sahin Kaymak
}

Accepted: 8 March 2015 / Published online: 19 March 2015

(C) Springer-Verlag Berlin Heidelberg 2015

Dear Editor:

We read with interest the article clinicopathological characteristics of colorectal cancer presenting under the age of 50 by Jones et al. [1] published online in the International Journal of Colorectal Disease. The authors analyzed the characteristics of colorectal cancer in a cohort under the age of 50. They have found that the poor differention of colorectal tumor was higher in the young patients without any effect on 5year overall survival. Also, they have stated that the majority of colorectal cancers presenting under the age of 50 were sporadic. We notice that explanation regarding some details of the patient population would be beneficial.

Although the study showed the clinicopathological features of the colorectal tumors, the evaluation of major risk factors related with the patients demographic would be meaningful. As it is known, the major risk factors for the colorectal cancers are family history, inflammatory bowel disease, diabetes, obesity, red meat consumption, processed meat consumption, smoking, and alcohol. These risk factors have relative risk between 1.2 and 4 for the colorectal cancer [2-5]. As the authors mention some of them in the introduction, the study did not focus on them. However, we consider that knowledge of these risk factors and correlation with clinicopathological characteristics in the patient population would be interesting to the readers.

\section{References}

1. Jones HG, Radwan R, Davies M, Evans M, Khot U, Chandrasekaran TV, Williams N, Murray A, Jones W, Harris D, Beynon J (2015) Clinicopathological characteristics of colorectal cancer presenting under the age of 50. Int J Colorectal Dis. doi:10.1007/s00384-015-2166-1

2. Huxley RR, Ansary-Moghaddam A, Clifton P, Czernichow S, Parr CL, Woodward M (2009) The impact of dietary and lifestyle risk factors on risk of colorectal cancer: a quantitative overview of the epidemiological evidence. Int J Cancer 125(1):171-180

3. Butterworth AS, Higgins JP, Pharoah P (2006) Relative and absolute risk of colorectal cancer for individuals with a family history: a metaanalysis. Eur J Cancer 42(2):216-227

4. Bernstein CN, Blanchard JF, Kliewer E, Wajda A (2001) Cancer risk in patients with inflammatory bowel disease: a population-based study. Cancer 91:854-862

5. American Cancer Society (2014) Colorectal Cancer Facts \& Figures 2014-2016. American Cancer Society, Atlanta
A. K. Coskun $(\triangle) \cdot$ S. Kaymak

Department of Surgery, Gulhane Military Medical Academy, Ankara, Turkey

e-mail: kagancoskun@gmail.com 